\title{
Regeneration in a mixed stand of native Pinus canariensis and introduced Pinus pinea species
}

\author{
José Ramón Arévalo $^{\mathrm{a}, *}$, Agustín Naranjo-Cigala ${ }^{\mathrm{b}}$, Marcos Salas Pascual ${ }^{\mathrm{c}}$ \\ ${ }^{a}$ Department of Ecology, Universidad de La Laguna, La Laguna 38206, Islas Canarias, Spain \\ ${ }^{\mathrm{b}}$ Department of Geography, Universidad de Las Palmas de Gran Canaria, Las Palmas de Gran Canaria 35003, Islas Canarias, Spain \\ ' Department of Plant Biology, Universidad de La Laguna, La Laguna 38206, Islas Canarias, Spain
}

Received 23 August 2004; accepted 1 March 2005

Available online 15 April 2005

\begin{abstract}
The main objective of our study is to determine whether regeneration of Pinus pinea (an exotic species) is spreading within a Pinus canariensis (native species) stand. The study area is located in the Natural Park of Tamadaba, $1400 \mathrm{~m}$ asl., in the NW of Gran Canaria Island (Canary Islands). Stems and regeneration of $P$. canariensis and $P$. pinea were mapped in five randomly selected plots where both species were planted together around 45 years ago. Densities and basal areas of both species were also recorded. $P$. canariensis demonstrated a greater ability to disperse than $P$. pinea. The two species showed different spatial patterns, with $P$. pinea tending toward a more aggregate spatial distribution of individuals than $P$. canariensis. Bivariate spatial relationships showed no difference from a random spatial distribution, indicating the lack of any pattern of aggregation or rejection between the species. These results indicated that $P$. pinea has not spread because it is less able to disperse (strongly barochorus) than P. canariensis (barochorus and anemochorus). Given that the future ability of $P$. pinea to disperse cannot be predicted, eradication of this species, together with additional plantings of $P$. canariensis in open areas, is proposed to restore the $P$. canariensis stand.
\end{abstract}

(C) 2005 Elsevier SAS. All rights reserved.

Keywords: Ripleys' K; Competition; Regeneration; Restoration; Canary Islands

\section{Introduction}

Non-native plants are important components of plant communities in many parts of the world (Mack et al., 2000). The spread of many pine species began soon after large-scale translocations around the world (Richardson, 1998; Richardson and Higgins, 1998; Richardson and Rejmánek, 2004). The introduction of exotic pines was partly motivated by the increased profits generated, and this promoted the invasion of species in new ecosystems once they had enough individuals, sufficient propagules and time to become established (Macdonald, 1984; Kruger et al., 1986). Richardson and Higgins (1998) demonstrated that biotic interactions are fundamental in determining communities' susceptibility to invasion by pines.

Spatial patterns are important characteristics of plant communities (Vacek and Lepš, 1996) and can be used to analyze

\footnotetext{
* Corresponding author.

E-mail address: jarevalo@ull.es (J.R. Arévalo).
}

tree species replacement (Horn, 1975; Woods, 1979; Busing, 1996), species regeneration (Condit et al., 1992), changes in plant communities after disturbance (Haase et al., 1997; Vacek and Lepš, 1996; Richardson and Higgins, 1998) and biological relationships between species such as competition (Hatton, 1989; Duncan, 1991), dispersion (Collins and Klahr, 1991), and adult-juvenile relationships (He et al., 1997). Consequently, the spatial distribution of plant individuals is important for the management of natural areas (Moeur, 1993).

Most afforestation on the island of Gran Canaria has been carried out with native species. The historical objective of the plantations that we analyzed in this study was to increase the density of the stand to protect against erosion in the watershed around dams (Salas, 1994). The primary species used was Pinus canariensis Sweet ex Spreng. However, some areas were planted with the exotic Mediterranean species Pinus pinea L. (2200 ha approximately). In the last 60 years, large areas of Gran Canaria have been reforested (Naranjo, 1995), but without subsequent management or monitoring. Richard- 
son et al. (1994) demonstrated that trees widely planted in alien environments can become naturalized and spread under certain circumstances. In recent years, experts and authorities have reconsidered the use of the plantations, moving away from the idea of using them solely as exploitable natural resources and towards the idea of managing them to restore the natural pine and laurel forests, which are largely disturbed and reduced to $25 \%$ of their potential area. Unfortunately, little information is available on the pine forests' dynamics, and the few existing quantitative studies deal specifically with fire effects (Höllermann, 2000; Arévalo et al., 2001).

The purpose of this study is to analyze the spatial distribution of seedlings and saplings of $P$. canariensis and $P$. pinea in areas where both species have been planted. Our main hypothesis is that regeneration of $P$. pinea has a low dispersion rate compared to $P$. canariensis, reducing the invasive capacity of the species. Recognizing the spatial regeneration characteristics of $P$. pinea as compared to $P$. canariensis can help to predict the ability of this exotic species to invade new areas, as has been seen in other ecosystems of the world (Richardson, 1989; Rouget et al., 2001).

\section{Material and methods}

\subsection{Study site}

The study was conducted on the north slope of the Tamadaba Natural Park, Gran Canaria $\left(28^{\circ} 19^{\prime} \mathrm{N}, 16^{\circ} 34^{\prime} \mathrm{W}\right)$, Canary Islands, Spain (Fig. 1). The park comprises 2000 ha, some areas of which have been reforested with pine species including $P$. canariensis, Pinus nigra, Pinus sylvestris and $P$. pinea. $P$. nigra and $P$. sylvestris were used in small areas (just a few hectares) and show poor regeneration. $P$. pinea was the exotic species most widely used in reforestation, with around 500 ha planted together with $P$. canariensis from 1950 to 1955 (Pérez et al., 1994). The plots we selected for analysis were located in these areas.

The annual precipitation of the park is $600 \mathrm{~mm}$ but fog drip can supplement inputs (Kämmer, 1974). The mean annual temperature is $16.8^{\circ} \mathrm{C}$. Frost events may occur a few days a year at higher altitude, but not in the study area. Because all the plots differ by less than $100 \mathrm{~m}$ in altitude, differences in average, maximum and minimum temperature are typically less than $1{ }^{\circ} \mathrm{C}$. Soils at the study site have been classified as per Haplumbrept and Xerochrept (Rodríguez, 2000). Fires were formerly frequent within the Park but, as the result of increased management over the past 50 years, fire intervals have been increased (Arévalo et al., 2001).

The dominant species is generally $P$. canariensis, although in some areas (including those selected for this study) $P$. pinea is now dominant. The understory, regardless of the dominant canopy species, is dominated by Cistus symphytifolius, Bystropogon origanifolius, Erica arborea, Chamaecytisus proliferus, Micromeria benthamii, Polycarpaea aristata, Sonchus acaulis and Neotinea maculata (Pérez et al., 1994). Nomenclature follows Izquierdo et al. (2001).

\subsection{Sampling design}

In April 2004, we randomly located five rectangular plots in the Natural Park of Tamadaba where $P$. pinea was planted (Table 1). The plots were of different sizes due to the features of the landscape, such as roads, ravines. In each plot we measured altitude and slope, and estimated canopy cover of the stand using a convex spherical densiometer (Lemmon, 1957). We also visually estimated rock, bare soil, and litter cover within each complete plot. Cover was estimated and noted on a scale of 1-10.

We defined trees as stems of at least $2.5 \mathrm{~cm}$ dbh, seedlings as stems less than $20 \mathrm{~cm}$ tall and saplings as stems taller than $20 \mathrm{~cm}$ and less than $2.5 \mathrm{~cm}$ dbh originating from seed. Previous studies recommended these classifications in concordance with the physiognomy and phenology of these species (Salas, 1994). We mapped all trees, seedlings and saplings in the plots to an accuracy of $0.05 \mathrm{~m}$.

\subsection{Statistical analysis}

We correlated the densities of the stems at each size class for both species in the five plots to determine the relationship between the size class distribution of both species in each plot (using the Pearson correlation coefficient, for $P<0.05$ and $n=7)$.

We studied the spatial distributions of $P$. canariensis and $P$. pinea in the five plots for the four different years using Ripley's univariate $K_{1}(t)$ function modified by Szwagrzyk (1990). This function determines the consistency of the empirical distribution of distances among individuals with Poisson expectations (Szwagrzyk and Czerwczak, 1993), and is given by the equation:

$K_{1}(t)=\frac{v(A)}{n^{2}} \sum_{x \in A} \sum_{y \in A \cup B} 1_{(0, t]}(\mathrm{d}(\mathrm{x}, y))$

In this analysis each plot was divided into an inner circle $(A)$ and a buffer zone $(B)$, where: $n=$ number of individuals per plot; $v(A)=$ area of the inner circle analyzed; $t=$ distance between individuals; $x, y=$ points of the Euclidean distance of the points $x$ and $y$.

The $K_{1}(t)$ function is transformed into a function $L_{1}(t)$ as follows:

$L_{1}(t)=\left(K_{1}(t) / \pi\right)^{0.5}$

The buffer zones were included to address the potential problem of edge effects (Ripley, 1977). To detect departure from complete spatial randomness (CSR), constant approximate confidence intervals were established by accepting the value $\pm 1.42(A / n-1)^{0.5}$ (where: $A=$ area of the inner circle, 

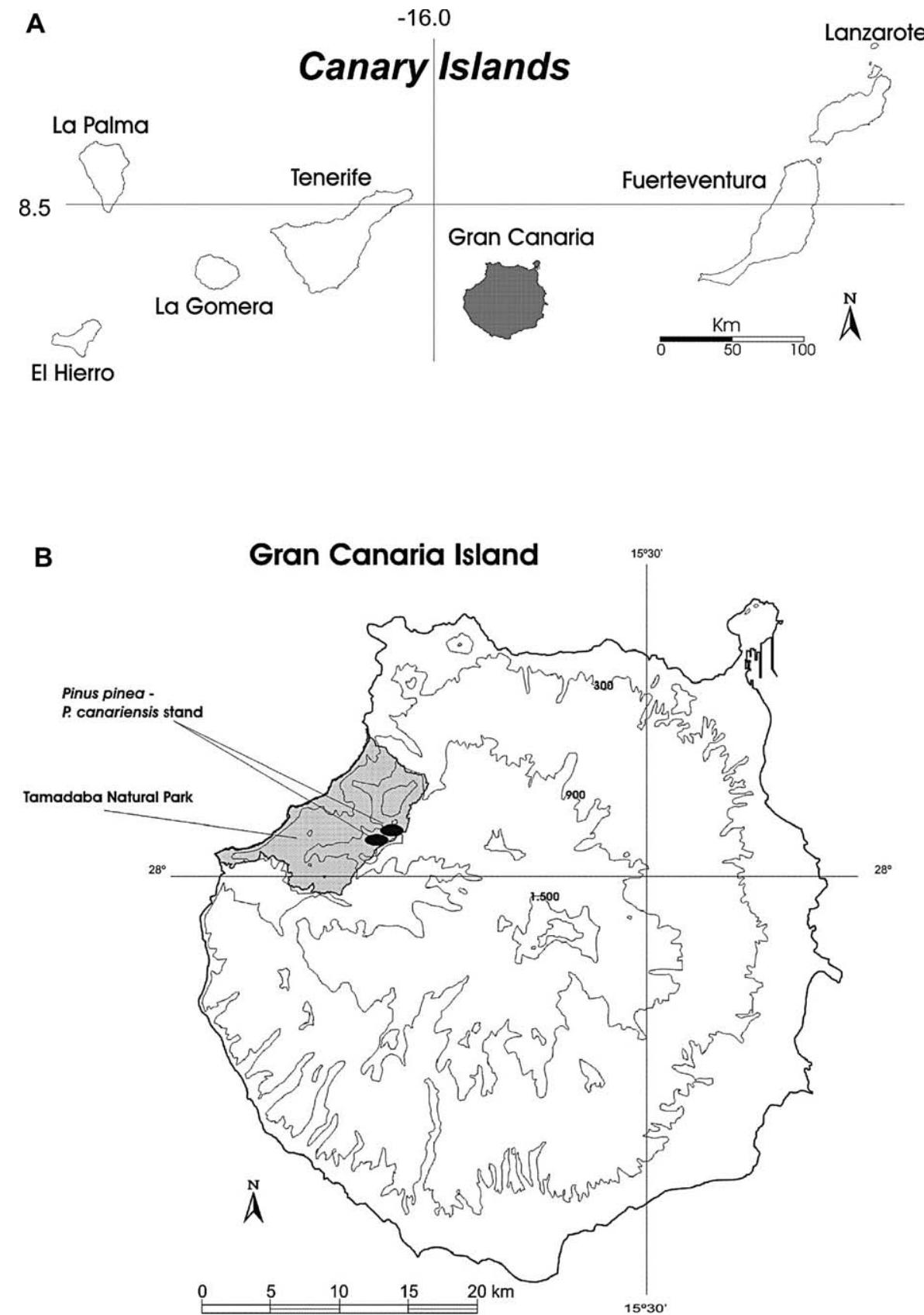

Fig. 1. (a) Canary Islands archipelago and (b) Gran Canaria Island indicating in grey the Natural Park of Tamadaba and in black the location of the study site (geographical coordinates are indicated).

Table 1

General abiotic information of the plots

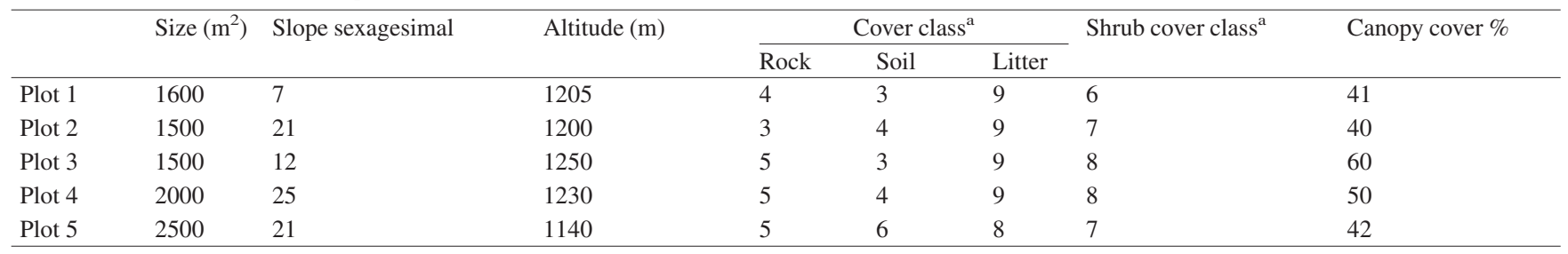

${ }^{\text {a }}$ Cover of the different parameters estimate visually in the total plot with the following cover classes: cover classes: $1:$ traces, $2:<1 \%$ of cover in the plot, 3 : $1-2 \%, 4: 2-5 \%, 5: 5-10 \%, 6: 10-25 \%, 7: 25-50 \%, 8: 50-75 \%, 9:>75 \%, 10: 100 \%$. 
Table 2

Trees (individuals of at least $2.5 \mathrm{~cm} \mathrm{dbh}$ ) basal area (PC: Pinus canariensis, PP: Pinus pinea, EA: Erica arborea), seedlings (stems less than $20 \mathrm{~cm}$ tall originating from seed) density and saplings (stems taller than $20 \mathrm{~cm}$ and less than $2.5 \mathrm{~cm}$ dbh originating from seed) density in the five plots of different size

\begin{tabular}{|c|c|c|c|c|c|c|c|c|}
\hline & \multicolumn{3}{|c|}{ Tree $\left(\mathrm{m}^{2} / \mathrm{ha}\right)$} & \multicolumn{3}{|c|}{ Sapling (ind/ha) } & \multicolumn{2}{|c|}{ Seedling (ind/ha) } \\
\hline & $\mathrm{PC}$ & $\mathrm{PP}$ & EA & $\mathrm{PC}$ & PP & EA & $\mathrm{PC}$ & PP \\
\hline Plot 1 & 12.51 & 3.91 & 0.00 & 550.00 & 6.25 & 0.00 & 843.75 & 131.25 \\
\hline Plot 2 & 3.85 & 10.86 & 0.00 & 433.33 & 313.33 & 0.00 & 1313.33 & 240.00 \\
\hline Plot 3 & 14.56 & 4.04 & 0.00 & 1560.00 & 140.00 & 0.00 & 4273.33 & 46.67 \\
\hline Plot 4 & 10.13 & 1.94 & 0.20 & 1120.00 & 195.00 & 25.00 & 3635.00 & 65.00 \\
\hline Plot 5 & 3.15 & 17.88 & 0.00 & 176.00 & 280.00 & 0.00 & 464.00 & 56.00 \\
\hline
\end{tabular}

and $n=$ number of trees in the plot) as a reasonable approximation of the $5 \%$ significance points (Ripley, 1979).

Spatial distributions of sapling and seedling P. canariensis and $P$. pinea were analyzed using the modified univariate $K_{1}(t)$ function. Transforming $K_{1}(t)$ to $W_{k}$ allowed us to graphically present the results by displaying the pattern across multiple scales. The indicator $W_{k}$ is used to estimate the departure of individuals' distributions from CSR (Szwagrzyk, 1990).

$W_{k}=\frac{\max _{t}\left(L_{1}(t)-t\right)}{S} \times \operatorname{sign}\left(L_{1}(t)-t\right)$

$\max \left(L_{1}(t)-t\right)=$ maximal deviation of the $L_{1}(t)$ function from CSR; $S=$ width of the confidence interval; $\operatorname{sign}\left(L_{1}(t)-\right.$ $t)=-1.0$, if $L_{1}(t)-t<0 ; \operatorname{sign}\left(L_{1}(t)-t\right)=1.0$, if $L_{1}(t)-t>0$.

Values of $W_{k}<-1$ indicate regular distribution of the individuals, while values $>1$ indicate clumped distribution or aggregation. When the spatial distribution of stems at a given distance does not differ from a random distribution (using a Monte Carlo test with 200 iterations of randomly generated $x, y$ coordinates), the value of the curve at that distance is zero. When significant aggregation was detected, the values of the curve were positive and higher than 1 (the value increased depending on the differences among the expected value and observed value). Negative values $W_{k}<-1$ indicate significant repulsion at the given distance.

To analyze the spatial relationship between two species we used the $K_{12}$ function for bivariate processes:

$K_{12}=\frac{v(A)}{n_{1} n_{2}} \sum_{x} \sum_{y} 1(0, t] \mathrm{d}(\mathrm{x}, y)$

where $n_{1}$ and $n_{2}$ are the number of objects of first and second type, $x$ is the object of the first type and $y$ is the object of the second type. The remaining symbols are as per the function $K_{1}$. As before, the values are transformed into $L_{12}$ and the $W_{k}$ function is then calculated. However, in this case, we obtain the $W_{12}$ by combining $K_{12}-K_{21}$, as results are not symmetrical (see Szwagrzyk and Czerwczak, 1993). With these methods we analyzed the spatial relationship between the pairs indicated in Appendix I.

Basic statistical methods followed Zar (1984) and were implemented using the SPSS statistical package (SPSS, 1986).

\section{Results}

The selected plots presented similar environmental characteristics, all having a canopy cover of 40-60\% and an understory cover class between 6 and 8 (Table 1).

Forest stand characteristics showed more variability between plots. Measured by basal area, P. pinea was dominant in plots 2 and 5, while $P$. canariensis was dominant in the remaining plots (Table 2). Measured by density, $P$. pinea dominated only plot 5 , while the rest of the plots were highly dominated by $P$. canariensis. Density in different diameter classes indicates that advanced regeneration (density at the smaller size classes) of $P$. pinea is only important in plot 4, while $P$. canariensis revealed notable advanced regeneration in all the plots except plot 5 (Fig. 2).

With respect to regeneration, all the plots were dominated by seedlings of $P$. canariensis. For seedlings, a large difference between the species was found in plot 5 (the plot dominated by $P$. pinea), with $P$. canariensis comprising $91 \%$ of seedlings and $P$. pinea comprising only $9 \%$. For saplings, plot 5 was dominated by $P$. pinea $(61 \%)$.

The correlation of the size class densities for each species in the five plots showed significant differences in some of the plots. The distributions of densities in different size classes were significantly different in plots 1, 2 and 4, while analysis of plots 3 and 5 did not reveal significant differences $(r$ $=0.978$ and $r=0.895$, respectively, and for both $P<0.01$ ).

Fig. 3 shows the $W_{k}$ transformation of the univariate Ripley's $K_{1}(t)$ for $P$. canariensis and $P$. pinea seedlings and saplings. There was significant seedling aggregation $\left(W_{k}>1\right)$ for $P$. canariensis at all the plots and distances analyzed while the importance of aggregation in P. canariensis saplings was not so noteworthy with no significance at any distance in plots 1, 2 and 5 (Fig. 3a, b). Values of $W_{k}>0.333$ and $W_{k}<1$ are considered intermediate between CSR and clumped (Szwagrzyk and Czerwczak, 1993). No over-dispersion $\left(W_{k}<1\right)$ at any of the analyzed distances was found for seedling or saplings at either site, even when the distribution of the stems results from a plantation program.

The results for $P$. pinea (Fig. 3c, d) contrast with those of $P$. canariensis, and show an increasing tendency to aggregate from seedlings to saplings. Aggregation, although significant at shorter distances in some of the plots, is not the dominant spatial distribution for seedlings. A random distribution of the seedlings was more common, while significant aggrega- 
A

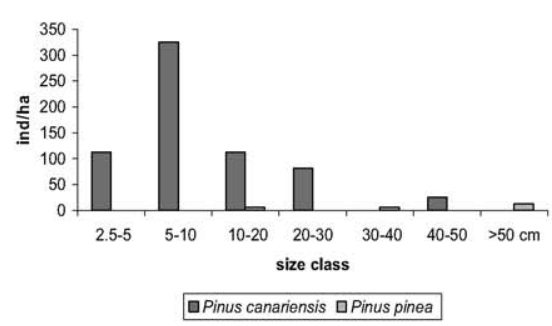

B

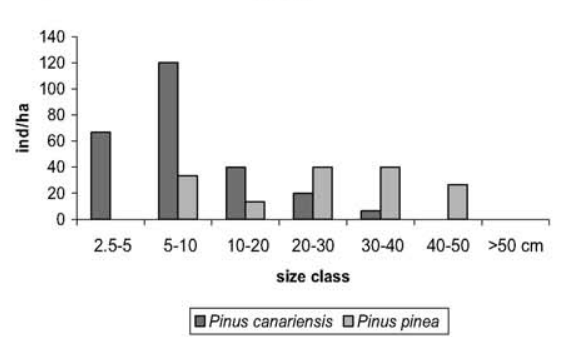

C

Plot 3

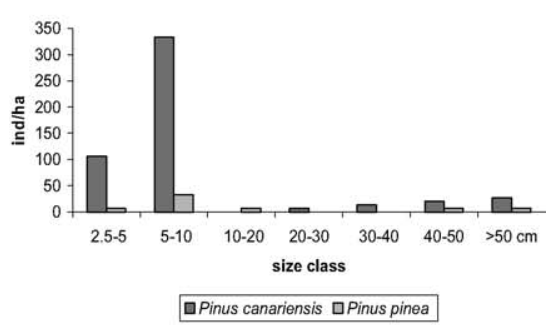

D Plot 4

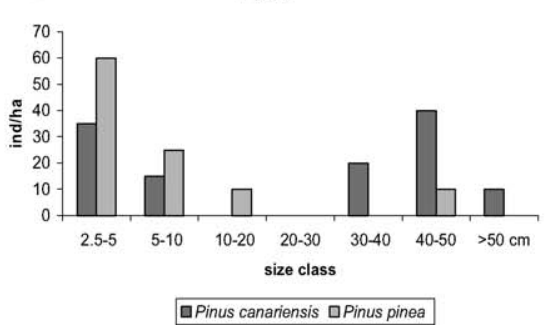

E

Plot 5

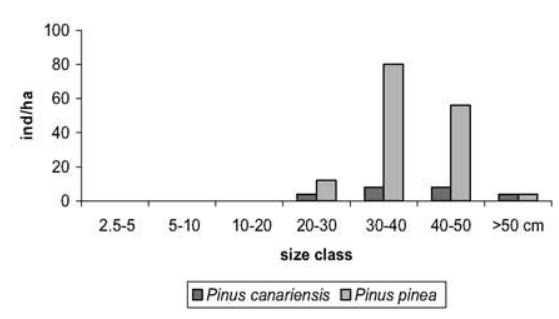

Fig. 2. Distribution of tree densities in different diameter classes for both species in the five plots.

A

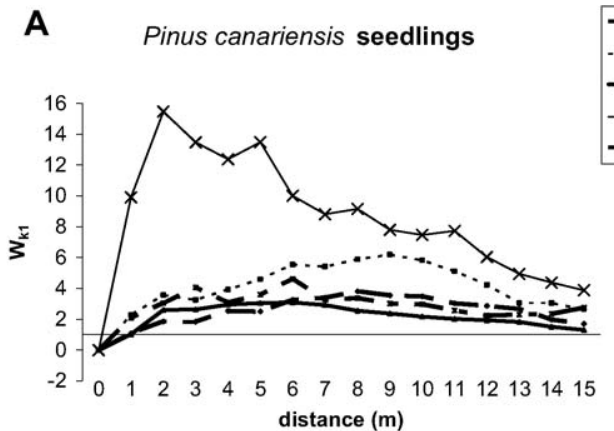

\section{B}

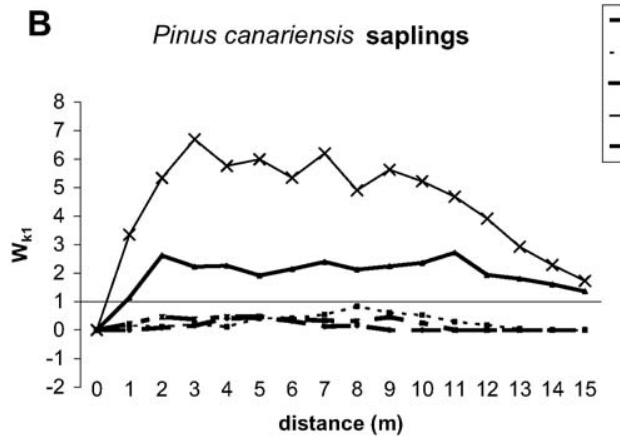

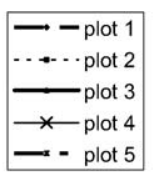

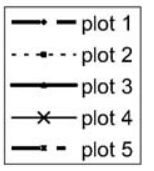

C

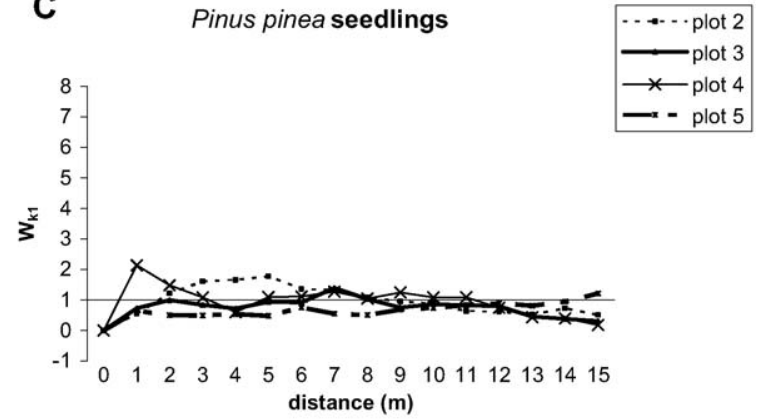

D

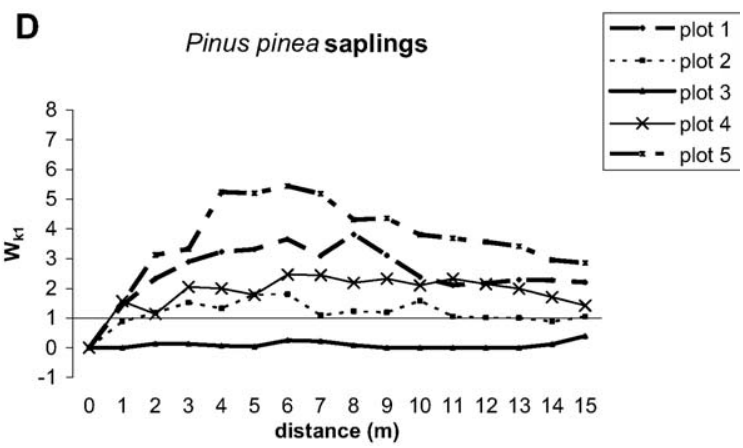

Fig. 3. Values of the $W_{k}$ index for seedlings and saplings of $P$. canariensis (a, b) and $P$. pinea (c, d). $W_{k}>1$ indicates a significantly clumped distribution, $W_{k}>$ 1 and $<0.333$ indicates an intermediate state between clumping and CSR. $W_{k}<-1$ indicates a significantly aggregated distribution, and $W_{k}>-1$ and $<-$ 0.333 indicates an intermediate state between aggregation and CSR. (plot 1 for $P$. pinea seedlings did not provide enough data to carry-out the analysis).

tion was the dominant pattern in P. pinea saplings (except in plot 3).

For the $W_{12}$ bivariate spatial analysis, all relationships between the stems of $P$. canariensis and $P$. pinea between seedling and saplings revealed no differences from a random spatial distribution (Appendix I).

\section{Discussion}

Phylogenetic studies have demonstrated that $P$. canariensis and $P$. pinea are highly genetically related species (Liston et al., 1999). Moreover, studies by Grotkopp et al. (2004) based on genome size found a strong relation between $P$. 
canariensis and P. pinaster, Pinus brutia, Pinus halepensis and $P$. pinea.

P. canariensis seeds are dispersed by wind. Frankis (1992) categorizes $P$. canariensis as an anemochorous species, as opposed to $P$. pinea, which has strongly barochorous dispersal in the Canary Islands. There is no information about any dispersal animal, although in other areas of the world it is dispersed by squirrels and jays (Grotkopp et al., 2004). This fact, combined with the dominance of $P$. canariensis surrounding the studied area, gives rise to the extensive regeneration of this species in most plots for seedlings and saplings regardless of canopy dominance (two of the plots are dominated by $P$. pinea according to density or basal area).

The density of the stems in different size classes also reveals that advanced regeneration of $P$. canariensis is greater than $P$. pinea. $P$. canariensis also showed higher density values in the smaller diameter size classes (except plot 4) (Fig. 2).

The univariate spatial analysis of trees revealed the existence of two different patterns: seedlings of $P$. canariensis showed a high aggregation index almost at all distances analyzed, becoming weaker and not significant in the saplings, while $P$. pinea showed a higher aggregation index in the saplings than in seedlings. Aggregations are related to the dependence of the species on environmental microheterogenity (Arévalo and Fernández-Palacios, 2003; Manabe and Yamamoto, 1997). We suggest that $P$. pinea can be more environmentally specific (with a higher dependence on natural disturbances such as fire) than $P$. canariensis, which can be considered more of a generalist species (Blanco et al., 1989). Initially, $P$. pinea seedlings grow with the nutrient provisions of the seed, but after the first few months, their higher dependence on environmental conditions will largely determine the probability of their becoming established.

The bivariate spatial analysis did not reveal any significant spatial relationships different from a random distribution at any of the distances analyzed (Appendix I). This suggests that the two species do not show any detectable biological interaction (over-dispersion or aggregation), perhaps due to genetic and ecological similarities (e.g. adaptation to fire or colonization of disturbed areas).

These results reveal that the importance of $P$. pinea in the stand is a function of human intervention, but the establishment and regeneration of the species is not safeguarded due to both the greater dispersal ability of $P$. canariensis and competition between the species for the same resources. We suggest that competition with $P$. canariensis combined with low numbers of $P$. pinea planted (we estimate around 2000 stems) will not allow the species to become naturalized and spread satisfactorily. However, some form of control is necessary to monitor and prevent this species from becoming invasive as has occurred in other ecosystems (Richardson, 1989; Rouget et al., 2001). There is little doubt of the damaging effects of introduced trees disrupting natural features of the native community (Peterken, 2001).

$P$. canariensis is highly adapted to regular burning and its establishment is probably favored over that of $P$. pinea, considering that native species are highly adapted to a regular occurrence of fire (Myers and Bazely, 2003). However, the frequency of fire in different protected areas of the Canary Islands has been reduced in the last 50 years (Arévalo et al., 2001). This means that over time, unless seedlings of $P$. canariensis are able to establish in higher numbers than those of $P$. pinea, the results will be unpredictable.

In conclusion, and as a result of both this uncertainty and the relatively small area to manage, we propose the cutting of stems of $P$. pinea and planting $P$. canariensis in the gaps in order to sufficiently suppress regeneration of the exotic species from the seed bank. These recommendations, based on the ecology and biology of the species are also in accordance with the laws of the Canarian Government requiring the elimination of exotic species. However, as Walters (1986) indicated, experimentation and quantification through monitoring provide the best adaptive management approach.

\section{Acknowledgements}

This work is part of the program of study of exotic species that is carrying-out the Invasive Species: Interinsular Research Group (EIGI) of the University of La Laguna and University of Las Palmas de Gran Canaria. We thank the students of Geography of University of Las Palmas de Gran Canaria and Gloria García Fariña from University of La Laguna for their assistant in the sampling. We are also grateful for the collaboration of the fine staff of the Cabildo de Gran Canaria (especially Mr. Carlos Velazquez and Mr. Eugenio Castro), who offered the use of their facilities in the Park. We thank Dr. Jonathan Price and Jerry Husak for their valuable comments on the manuscript, and Heather Adams for revising the English edition. We thank the associate editor, Bill Loneragan, and two anonymous referees for their constructive comments on the manuscript. 


\section{Appendix I}

A.1. Values of the $W_{12}$ index in each plot, trees of P. canariensis and P. pinea and P. canariensis seedlings (Pc_se), saplings $\left(P c \_s a\right), P$. pinea seedlings ( $P$ __se) and saplings $\left(P p \_s a\right)$

\begin{tabular}{|c|c|c|c|c|c|c|c|}
\hline \multicolumn{4}{|l|}{ Plot 1} & \\
\hline \multicolumn{4}{|c|}{ Pinus canariensis } & \multicolumn{4}{|c|}{ Pinus pinea } \\
\hline$\overline{P C \_s e}$ & Pc_sa & Pp_se & p_sa & \multicolumn{4}{|c|}{ Pc_se Pc_sa Pp_se Pp_sa } \\
\hline 0 & 0 & $0 \quad 0$ & - & 0 & 0 & 0 & - \\
\hline 0 & 0 & 0 & - & 0 & 0 & 0 & - \\
\hline 0 & 0 & 0 & - & 0 & 0 & 0 & - \\
\hline 0 & & -0.100 & - & 0 & 0 & 0 & - \\
\hline 0 & 0 & $0 \quad 0$ & - & 0 & 0 & 0 & - \\
\hline 0 & 0 & 0 & - & 0 & 0 & 0 & - \\
\hline 0 & 0 & 0 & - & 0 & 0 & 0 & - \\
\hline 0 & 0 & 0 & - & 0 & 0 & 0 & - \\
\hline 0 & 0 & 0 & - & 0 & 0 & 0 & - \\
\hline 0 & & -0.022 & - & 0 & 0 & 0 & - \\
\hline 0 & & -0.021 & - & 0 & 0 & 0 & - \\
\hline 0 & & -0.040 & - & 0 & 0 & 0 & - \\
\hline 0 & & -0.053 & - & 0 & 0 & 0 & - \\
\hline 0 & $3 E-04$ & $4-0.063$ & - & 0 & 0 & 0 & - \\
\hline 0 & 0.006 & -0.069 & - & 0 & 0 & 0 & - \\
\hline 0 & & -0.055 & - & 0 & 0 & 0 & - \\
\hline \multicolumn{8}{|l|}{ Plot 4} \\
\hline \multicolumn{4}{|c|}{ Pinus canariensis } & \multicolumn{4}{|c|}{ Pinus pinea } \\
\hline Pc_se & Pc_sa & Pp_se & p_sa & \multicolumn{4}{|c|}{ Pc_se Pc_sa Pp_se Pp_sa } \\
\hline 0 & 0 & $0 \quad 0$ & 0 & 0 & 0 & 0 & 0 \\
\hline 0 & 0 & 0 & 0 & 0 & 0.028 & 0 & 0 \\
\hline 0 & 0 & 0 & 0 & 0 & 0 & 0 & 0 \\
\hline 0 & 0 & 0 & 0 & 0 & 0.031 & 0 & 0 \\
\hline 0 & 0 & 0 & 0 & 0 & 0 & 0 & 0.065 \\
\hline 0 & 0.079 & 0 & 0 & 0 & 0 & 0 & 0.028 \\
\hline 0 & 0.216 & 0 & 0 & 0 & 0 & 0 & 0 \\
\hline 0 & 0.230 & 0 & 0 & 0 & 0 & 0 & 0 \\
\hline 0 & 0.114 & 0 & 0 & 0 & 0 & 0 & 0 \\
\hline 0 & 0 & 0 & 0 & 0 & 0 & 0 & 0 \\
\hline 0 & 0 & 0 & 0 & 0 & 0 & 0 & 0.033 \\
\hline 0 & 0 & 0 & 0 & 0 & 0 & 0 & 0.036 \\
\hline 0 & 0 & 0 & 0 & 0 & 0 & 0 & 0.025 \\
\hline 0 & 0.065 & 0 & 0 & 0 & 0 & 0 & 0.026 \\
\hline 0.014 & 0.064 & 0 & 0 & 0 & 0 & 0 & 0.050 \\
\hline 0.008 & 0.011 & 0 & 0 & 0 & 0 & 0 & 0.016 \\
\hline
\end{tabular}

\section{References}

Arévalo, J.R., Fernández-Palacios, J.M., Jiménez, M.J., Gil, P., 2001. The effect of fire in the understory of two reforested stands of Pinus canariensis. Tenerife. Canary Islands. For. Ecol. Manage. 148, 21-29.

Arévalo, J.R., Fernández-Palacios, J.M., 2003. Spatial patterns of trees and juveniles in a laurel forest in Tenerife, Canary Islands. Plant Ecol. 165, $1-10$.

Blanco, A., Castroviejo, M., Fraile, J.L., Gandullo, J.M., Muñoz, L.A., Sánchez, O., 1989. Estudio Ecológico del Pino Canario. Serie Técnica No. 6. Ministerio de Agricultura, Pesca y Alimentación, Madrid.

Busing, R.T., 1996. Estimation of tree replacement in an Appalachian Picea-Abies forest. J. Veg. Sci. 7, 685-694.

Collins, S.L., Klahr, S.C., 1991. Tree dispersion in oak-dominated forest along an environmental gradient. Oecologia 86, 471-477.

Condit, R., Hubbell, S.P., Foster, R.B., 1992. Recruitment near nonspecific adults and the maintenance of tree and shrub diversity in a neotropical forest. Am. Nat. 140, 261-286.

Duncan, R.D., 1991. Competition and the coexistence of species in a mixed podocarp stand. J. Ecol. 79, 1073-1084.

Frankis, M.P., 1992. Conifers of Tenerife. Conifer Soc. Aust. Newsletter 11, 5-7.

Grotkopp, E., Rejmánek, M., Sanderson, M.J., Rost, T.L., 2004. Evolution of genome size in pines (Pinus) and its life-history correlates: super-tree analyses. Evolution 58, 1705-1729.

Hatton, T.J., 1989. Spatial patterning of sweet briar (Rosa rubignosa) by vertebrate species. Aust. J. Ecol. 14, 199-205.

Haase, P., Pugnaire, F.I., Clark, S.C., Incoll, L.D., 1997. Spatail pattern in Anthyllis cytisoides shrubland on abandoned land in southerstern Spain. J. Veg. Sci. 8, 627-634.

He, F., Legendre, P., LaFrankie, J.V., 1997. Distribution patterns of tree species in a Malaysian tropical rain forest. J. Veg. Sci. 8, 105-114.
Höllermann, P., 2000. The impact of fire in canarian ecosystems 1983-1998. Erkunde 54, 70-75.

Horn, H.S., 1975. Markovian processes of forest succession. In: Cody, M., Diamond, J. (Eds.), Ecology and Evolution of Communities. Belknap Press, Cambridge, MA, pp. 196-211.

Izquierdo, I., Martín, J.L., Zurita, N., Arechavaleta, M. (Eds.), 2001. Lista de especies silvestres de Canarias (hongos, plantas y animales terrestres). Consejería de Política Territorial y Medio Ambiente Gobierno de Canarias.

Kämmer, F., 1974. Klima und vegetation auf Tenerife, besonders in Hinblick auf den Nebelniederschlag. Scripta Geobotanica 7, 1-78.

Kruger, F.J., Richardson, D.M., Van Wilgen, B.W., 1986. Processes of invasions by alien plants. In: Macdonald, A.W., Kruger, F.J., Ferrar, A.A. (Eds.), The Ecology and Management of Biological Invasions in Southern Africa. Oxford Press, Cape Town, pp. 145-155.

Lemmon, P.E., 1957. A new instrument for measuring forest overstory density. J. Forestry 55, 667-669.

Liston, A., Robinson, W.A., Piñero, D., Alvarez-Buylla, E.R., 1999. Phylogenetics of Pinus (Pinacea) bases on nuclear ribosomal DNA internal transcribe spacer region sequences. Mol. Phylogenet. Evol. 11, 95-109.

Macdonald, I.A.W., 1984. Is the fynbos specially susceptible to invasion by alien plants? A re-analysis of available data. S. Afr. J. Sci. 80, 369-377.

Mack, R., Simberloff, D., Lonsdale, W., Evans, H., Clout, M., Bazzaz, F., 2000. Biotic invasions: causes, epidemiology, global consequences, and control. Ecol. Appl. 10, 689-710.

Manabe, T., Yamamoto, S.I., 1997. Spatial distribution of Eurya japonica in an old-growth evergreen broad-leaved forest, SW Japan. J. Veg. Sci. 8, 761-772.

Myers, J.H., Bazely, D.R., 2003. Ecology and control of introduce plants. Cambridge University Press, Cambridge.

Moeur, M., 1993. Characterizing spatial patterns of trees using stemmapped data. For. Sci. 39, 756-775. 
Naranjo, A., 1995. Evolución del paisaje vegetal en la Cumbre Central de Gran Canaria (1960-1992). Servicio de publicaciones (Universidad de Las Palmas de Gran Canaria). Ediciones del Cabildo Insular de Gran Canaria.

Peterken, G.F., 2001. Ecological effects of introduced tree species in Britain. For. Ecol. Manage. 141, 31-42.

Pérez, P.L., Salas, M., Rodríguez, O., Acebes, J.R., del Arco, M., Wildpret, W., 1994. Atlas cartográfico de los pinares canarios IV: Gran Canaria y plantaciones de Fuerteventura y Lanzarote. Viceconsejería de Medio Ambiente S/C de Tenerife).

Richardson, D.M., 1989. The ecology of invasions by Pinus (Pinaceae) and Hakea (Proteaceae) species, with special emphasis on patterns, processes and consequences of invasion in mountain fynbos of the southwestern Cape Province, South Africa. Ph.D. diss. University of Cape Town, Cape Town.

Richardson, D.M., 1998. Forestry trees a invasive aliens. Conserv. Biol. 12, $18-26$.

Richardson, D.M., Higgins, S.I., 1998. Pines as invaders in the southern hemisphere. In: Richardson, D.M. (Ed.), Ecology and Biogeography of Pinus. Cambridge University Press, Cambridge, pp. 450-473.

Richardson, D.M., Rejmánek, M., 2004. Invasive conifers: a global survey and predictive framework. Diversity Distributions 10, 321-331.

Richardson, D.M., Williams, P.A., Hobbs, R.J., 1994. Pine invasions in the southern hemisphere: determinants of spread and invadability. J. Biogeogr. 21, 511-527.
Ripley, B.D., 1977. Modelling spatial patterns. J. R. Stat. Soc. B 39, 172212.

Ripley, B.D., 1979. Test of 'randomness' for spatial point patterns. J. R. Stat. Soc. Ser. B Methodological 41, 368-374.

Rodríguez, A., 2000. El Suelo. In: Morales, G., Pérez, R. (Eds.), Gran atlas temático de Canarias. Ed. Interinsular Canarias, Tenerife, pp. 107120 S/C de.

Rouget, M., Richardson, D.M., Milton, S.J., Polakow, D., 2001. Predicting invasion dynamics of four alien Pinus species in a highly fragmented semi-arid shrubland in South Africa. Plant Ecol. 152, 79-92.

Salas, M., 1994. Estudio del Área Potencial y Serie de los Pinares Grancanarios (Islas Canarias-España). Ph.D. diss. Universidad de La Laguna. La Laguna.

Szwagrzyk, J., 1990. Regeneration of forest related to the spatial structure of trees: a study of two forest communities in Western Carpathians, southern Poland. Vegetatio 89, 11-22.

Szwagrzyk, J., Czerwczak, M., 1993. Spatial patterns of trees in natural forest of East-Central Europe. J. Veg. Sci. 4, 469-479.

SPSS, 1986. SPSS/PC+ V.6.0. Base manual. SPSS Inc., Chicago, IL.

Vacek, S., Lepš, J., 1996. Spatial dynamics of forest decline: the role of neighboring trees. J. Veg. Sci. 7, 789-798.

Walters, C., 1986. Adaptive Management of Removable Resources. Macmillan, New York.

Woods, K.D., 1979. Reciprocal replacement and the maintenance of codominance in a beech-maple forest. Oikos 33, 31-39.

Zar, J.H., 1984. Biostatistical Analysis, second ed. Prentice-Hall, Englewood Cliffs, NJ. 